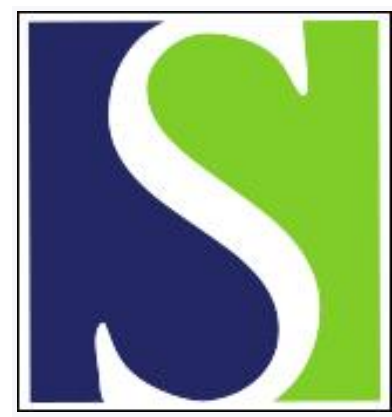

Scand J Work Environ Health 2009;35(6):466-474

https://doi.org/10.5271/sjweh.1357

Published online: 21 Oct 2009, Issue date: 00 Dec 2009

The interplay between physical activity at work and during leisure time - risk of ischemic heart disease and all-cause mortality in middle-aged Caucasian men

by Holtermann A, Mortensen OS, Burr H, Søgaard K, Gyntelberg F, Suadicani P

Affiliation: National Research Centre for the Working Environment, 2100 Copenhagen $\varnothing$, Denmark. aho@nrcwe.dk

Refers to the following texts of the Journal: 2007;33(6):405-424 2007;33(6):425-434

The following articles refer to this text: 2009;35(6):401-402; 2010;36(5):357-365; 2010;36(5):366-372; 2010;36(5):349-355; 2011;37(1):6-29; 2010;36(6):466-472; 2016;42(4):291-298

Key terms: all-cause mortality; cardiovascular health; health; IHD; ischemic heart disease; leisure time; mortality; occupational health; occupational physical activity; physical activity; risk; work

This article in PubMed: www.ncbi.nlm.nih.gov/pubmed/19851700 


\title{
The interplay between physical activity at work and during leisure time - risk of ischemic heart disease and all-cause mortality in middle-aged Caucasian men
}

\author{
by Andreas Holtermann, PhD, ${ }^{1}$ Ole Steen Mortensen, PhD, ${ }^{1,2}$ Hermann Burr, PhD, ${ }^{1}$ Karen Søgaard, PhD, ${ }^{3}$ \\ Finn Gyntelberg, DMSc, ${ }^{2}$ Poul Suadicani, DMSc ${ }^{2}$
}

\begin{abstract}
Holtermann A, Mortensen OS, Burr H, Søgaard K, Gyntelberg F, Suadicani P. The interplay between physical activity at work and during leisure time - risk of ischemic heart disease and all-cause mortality in middle-aged Caucasian men. Scand J Work Environ Health. 2009;35(6):466-474.
\end{abstract}

\begin{abstract}
Objective Our aim was to test the hypothesis that a high level of physical activity during leisure time increases the risk of ischemic heart disease (IHD) mortality among men with high physical work demands.

Methods We carried out a 30-year follow-up of the Copenhagen Male Study of 5249 caucasian, male workers aged 40-59 years; 274 men with overt cardiovascular disease were excluded from the follow-up.

Results During the follow-up period, 591 men (11.9\%) died from IHD. Cox analyses of men with low (N=1236), medium $(\mathrm{N}=2651)$, and high $(\mathrm{N}=858)$ physical work demands showed that those with high demands had a higher risk of IHD mortality compared to men with low demands [age-adjusted hazard ratio $1.51,95 \%$ confidence interval $(95 \%$ CI $) 1.18-1.94]$. In all three groups, men with a low level of physical activity during leisure time had a higher risk of IHD than men with a medium or high level. Overall, the age-adjusted hazard ratio for IHD mortality associated with a high level of leisure time physical activity was 0.49 (95\% CI $0.34-0.70)$. Among workers with high physical work demands, the hazard ratio for IHD mortality (adjusted for confounders) was 0.82 (95\% CI $0.42-1.56$ ) for a high level of leisure time physical activity and 0.62 (95\% CI $0.40-0.97)$ for a moderate level.

Conclusion We did not find support for the hypothesis that a high level of physical activity during leisure time increases the risk of IHD mortality among men with high physical work demands and with no pre-existing clinical cardiovascular disease. In contrast, moderate and high levels of activity during leisure time seemed to be protective against IHD mortality among people with medium and high physical activity at work.
\end{abstract}

Key terms cardiovascular health; occupational health; occupational physical activity.

A sedentary lifestyle is associated with an increased risk of premature cardiovascular and all-cause mortality (1-6); by implication, individuals engaged in high levels of physical activity during leisure time are at a much lower risk of premature death (7-10). Recommending such activity is accordingly reasonable for the promotion of public health (11).

Conflicting results characterize the existing scientific literature on the association between physical activity at work and cardiovascular health. In some studies, a high occupational physical activity has been reported to reduce the risk of coronary heart disease (12), cardiovascular mortality $(13,14)$, and all-cause mortality $(8,15)$, and has therefore been recommended for the promotion of public health (16). In contrast, other studies have reported an increased risk of cardiovascular disease and premature mortality resulting from a high level of occupational physical activity (17-21). The public recommendations for health-promoting physical activity do not distinguish between physical activity occurring at the workplace or during leisure time (11). Accordingly, in order to prescribe health-promoting physical activity in a working population, additional scientific documentation regarding the influence of occupational physical activity on cardiovascular health and longevity is required.

1 National Research Centre for the Working Environment, Copenhagen, Denmark.

2 The Copenhagen Male Study, Epidemiological Research Unit, Department of Occupational and Environmental Medicine, Bispebjerg University Hospital, Copenhagen, Denmark.

3 Institute of Sport Science and Clinical Biomechanics, University of Southern Denmark, Odense M, Denmark.

Correspondence to: PhD A Holtermann, National Research Centre for the Working Environment, Lersø Parkallé 105, 2100 Copenhagen $\varnothing$, Denmark. [E-mail: aho@nrcwe.dk] 
Two centuries ago it was suggested that - among workers with physically demanding work - high levels of physical activity during leisure time might impair, rather than promote, cardiovascular health (22). The idea that individuals with high physical work demands should abstain from physical activity during leisure time has been supported by reports showing an increased risk of high systolic blood pressure (23), cardiovascular disease (17-19), and premature mortality $(20,21)$ among these workers. These excess risks have previously been attributed to a prolonged intravascular turbulence and reduced wall shear stress (18), inducing inflammatory processes in the arterial walls leading to atherosclerosis (24). In a recent epidemiological study of high methodological quality, Krause et al (18) did not find any protective effect of physical activity during leisure time regarding 4- or 11-year progression of atherosclerosis. Because the international physical activity recommendations do not take physical work demands into consideration (11), investigation of the effects of physical activity during leisure time on workers with different physical work demands is needed.

We investigated if a high physical work demand enhances the risk of IHD and all-cause mortality, and tested the hypothesis that a high level of physical activity during leisure time elevates the risk of IHD and all-cause mortality among workers with high physical demands.

\section{Material and methods}

The Copenhagen Male Study was established in 19701971 and comprised 5249 (87\% of those invited to participate) male employees, aged 40-59 years, from 14 companies in the railway, public road construction, military, postal and telephone services, customs, national banking, and medical industries $(25,26)$.

The examination consisted of a questionnaire, a short interview, and a clinical examination including measurements of height, weight, and blood pressure. From the questionnaire, information was obtained about working conditions, lifestyle, and general health, including history of myocardial infarction, angina pectoris, and intermittent claudication. The information given in the questionnaire was clarified with each subject in the ensuing interview. Details on the questionnaire have already been published (27). A number of these factors are elaborated in more detail below.

\section{Physical activity at work}

Physical activity at work was estimated by the question: "Which description most precisely covers your pattern of physical activity at work?" Groups were defined according to the following responses: (i) You are mainly sedentary and do not walk much around at your workplace, eg, desk work, and work including assembling of minor parts (group 1); (ii) You walk around quite a bit at your workplace but do not have to carry heavy items, eg, light industrial work, non-sedentary office work, inspection and the like (group 2); (iii) Most of the time you walk, and you often have to walk up stairs and lift various items. Examples include mail delivery and construction work (group 3); (iv) You do heavy physical work. You carry heavy burdens and carry out physically strenuous work, eg, work including digging and shoveling (group 4). In the analyses, physical activity was defined as follows: group $1=$ low; group 2=moderate; and group 3=high (only $2.4 \%$ belonged to group 4, so groups 3 and 4 were pooled).

Strenuous work was estimated from the question: "Do you perform strenuous work (work resulting in sweating)?" The answer options were: "often", "occasionally", and "seldom or never" and coded as follows: $1=$ seldom or never, $2=$ occasionally, and $3=$ often.

An additional variable was constructed in order to further distinguish between the presence or absence of physically demanding work. Summing up the values from the aforementioned questions on physical activity and strenuous work gave values ranging from 2-6. A low combined score of 2 was defined as "low physical work demands", a score of 3 or 4 was defined as "moderate physical work demands", and a score of 5 or 6 was defined as "high physical work demands".

\section{Physical activity during leisure time}

In order to determine this factor, the questionnaire asked "Which description most precisely covers your pattern of physical activity at leisure time?" with the following possible responses: (i) You are mainly sedentary, for example, you read, watch television, go to the cinema. In general you spend most of your leisure time performing sedentary tasks (group 1); (ii) You go for a walk, use your bicycle a little or perform activity for at least 4 hours per week, for example, light gardening, leisure-time building activity, table tennis and bowling (group 2); (iii) You are an active athlete, run, play tennis or badminton for at least 3 hours/week. If you frequently perform heavy gardening, you also belong to this group (group 3); (iv) You take part in competitive sports, swim, play European football, handball or run long distances regularly several times per week (group 4).

In the analyses, the level of physical activity during leisure time was defined as group $1=$ low, group $2=$ moderate, and group $3=$ high (since only $0.4 \%$ belonged to group 4, groups 3 and 4 were pooled). 


\section{Lifestyle factors}

The male workers reported if they were current smokers, previously smoked, or had never smoked. In addition, participants reported their daily average alcohol consumption as the number of alcoholic beverages consumed per day in the following categories: $0,1-2$, $3-5,6-10$, and $>10$.

\section{Clinical and health related factors}

Based on height and weight measurements, body mass index was calculated as $\mathrm{kg} / \mathrm{m}^{2}$. Blood pressure was measured with the subject seated and after at least five minutes rest. A $12 \mathrm{~cm}$ wide, $26 \mathrm{~cm}$ long cuff was firmly and evenly applied to the right upper arm with the lower edge of the cuff placed $2 \mathrm{~cm}$ antecubitally. Diastolic blood pressure was recorded at the point where the Korotkoff sounds disappeared (phase 5). In addition, the participants were asked if they received treatment for either hypertension or diabetes from their physician or elsewhere. The answer options were yes or no.

\section{Social class}

The men were divided into five social classes according to a system originally elaborated by Svalastoga and later adjusted by Hansen $(28,29)$ This classification system is based on education level and job position in terms of the number of subordinates. Typical jobs in the study cohort were: (i) officer, civil engineer, office executive, or head of department (social class I); (ii) head clerk or engineer (social class II); engine driver or train guard (social class III); machine fitter in a telephone company (social class IV); and unskilled laborer, mechanic, or driver (social class V).

\section{Eligibility}

Men with a history of myocardial infarction $(\mathrm{N}=74)$, angina pectoris $(\mathrm{N}=165)$ or intermittent claudication $(\mathrm{N}=105)$ at baseline were excluded from our prospective study. In total, this group comprised 274 men. Moreover, nine men had missing answers, and 14 had emigrated during the follow-up leaving 4952 men eligible for

Table 1. Lifestyle and other characteristics stratified on occupational physical activity among men without history of myocardial infarction, angina pectoris, or intermittent claudication. Values presented are mean (SD) or frequency in percentage.

\begin{tabular}{|c|c|c|c|c|c|c|c|c|c|c|c|}
\hline \multirow[t]{3}{*}{ Lifestyle factors 1970-1971 } & \multicolumn{9}{|c|}{ Level of occupational physical activity } & \multirow[t]{3}{*}{ P-value ${ }^{a}$} & \multirow[t]{3}{*}{ P-value } \\
\hline & \multicolumn{3}{|c|}{ Low $(\mathrm{N}=1415)$} & \multicolumn{3}{|c|}{ Moderate $(\mathrm{N}=2526)$} & \multicolumn{3}{|c|}{ High $(N=905)$} & & \\
\hline & Mean & SD & $\begin{array}{c}\text { Frequency } \\
(\%)\end{array}$ & Mean & SD & $\begin{array}{c}\text { Frequency } \\
(\%)\end{array}$ & Mean & SD & $\begin{array}{c}\text { Frequency } \\
(\%)\end{array}$ & & \\
\hline \multicolumn{12}{|l|}{ Leisure time physical activity } \\
\hline Low & . & & 18.7 & . & . & 16.1 & . & . & 16.1 & & \\
\hline Moderate & . & & 70.8 & . & . & 74.8 & . & . & 70.2 & 0.02 & 0.001 \\
\hline High & . & . & 10.6 & . & . & 9.1 & . & . & 13.7 & & \\
\hline \multicolumn{12}{|l|}{ Smoker } \\
\hline Current & . & . & 67.0 & . & . & 72.8 & . & . & 75.7 & & \\
\hline Previous & . & . & 21.8 & . & . & 18.8 & . & . & 16.1 & $<0.001$ & $<0.001$ \\
\hline Never & . & . & 11.2 & . & . & 8.4 & . & . & 8.2 & & \\
\hline \multicolumn{12}{|l|}{ Alcohol, beverages per 24 hours } \\
\hline 0 & . & . & 38.0 & . & . & 34.2 & . & . & 26.7 & & \\
\hline $1-2$ & . & . & 50.6 & . & . & 47.3 & . & . & 43.2 & $<0.001$ & $<0.001$ \\
\hline $3-5$ & . & . & 10.3 & . & . & 15.6 & . & . & 23.6 & & \\
\hline$\geq 6$ & $\cdot$ & . & 1.1 & $\cdot$ & . & 2.9 & . & . & 6.5 & & \\
\hline Age (years) & 48.7 & 5.3 & & 48.6 & 5.3 & & 48.7 & 5.2 & . & 0.98 & 0.36 \\
\hline Body mass index $\left(\mathrm{kg} / \mathrm{m}^{2}\right)$ & 24.8 & 2.8 & & 25.4 & 3.0 & & 25.8 & 3.1 & . & $<0.001$ & 0.16 \\
\hline Low social class (classes IV/V) & . & . & 23.5 & . & . & 58.4 & . & . & 92.4 & $<0.001$ & $<0.001$ \\
\hline \multicolumn{12}{|l|}{ Clinical risk factors } \\
\hline Diabetes $^{c}$ & . & . & 0.9 & . & . & 0.6 & . & . & 1.0 & 0.91 & 0.28 \\
\hline Systolic blood pressure (mm Hg) & 134.8 & 18.4 & & 134.6 & 19.0 & & 134.1 & 19.5 & . & 0.40 & 0.85 \\
\hline Diastolic blood pressure $(\mathrm{mm} \mathrm{Hg})$ & 83.3 & 11.3 & & 82.8 & 11.4 & & 82.8 & 11.8 & . & 0.25 & 0.41 \\
\hline Hypertensiond & . & . & 1.6 & . & . & 1.7 & . & . & 1.4 & 0.80 & 0.86 \\
\hline
\end{tabular}

a P-values of trend test (Kendall's tau B) or test for linearity in analysis of variance.

b $\mathrm{P}$-values of Chi-square test or test for deviation in analysis of variance.

c Receives doctor's treatment due to diabetes.

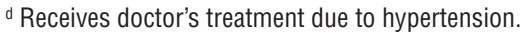


the analyses. With respect to all the variables included, missing values ranged from $0-2.7 \%$.

\section{End-points}

We obtained information on death diagnoses between the period 1970-1971 to the end of 2001 from official national registers. The IHD mortality diagnoses included International Classification of Diseases' codes ICD-8: 410-14, and (from 1994) ICD-10: I20-I25. These diagnoses predominantly comprised acute myocardial infarction and arteriosclerotic heart disease.

\section{Statistical analyses}

We performed basic statistical analyses, Chi-squared analysis (likelihood ratio), analysis of variance, and regression analyses. We estimated relative risks by exp $(\beta)$, where $\beta$ is the hazard coefficient for the variable of interest in a Cox's proportional hazards regression model with the maximum likelihood ratio method. Assumptions regarding the use of Cox's proportional hazards were met by inspection of the log minus log function at the covariate mean. We took, a priori, as significant a two-sided probability value of $\mathrm{P} \leq 0.05$. The number of subjects in the different tables may vary due to differences in the number of missing observations in the separate analyses.

\section{Results}

In the eligible study population of male workers, 591 died $(11.9 \%)$ from IHD mortality between the period 1970-1971 to the end of 2001. During the same period, 2677 (54.1\%) male workers died in total.

Table 1 illustrates lifestyle and other characteristics stratified into low, moderate, and high occupational physical activity among male workers without a history of myocardial infarction, angina pectoris, or intermittent claudication. The level of occupational physical activity was strongly associated with social class. We observed only minor, but significant differences in the level of physical activity during leisure time between male workers with different levels of occupational physical

Table 2. Lifestyle and other characteristics stratified on occurrence of physically strenuous work among men without history of myocardial infarction, angina pectoris, or intermittent claudication.

\begin{tabular}{|c|c|c|c|c|c|c|c|c|c|c|c|}
\hline \multirow[t]{3}{*}{ Lifestyle factors $1970-1971$} & \multicolumn{9}{|c|}{ Level of physical strenuous work (resulting in sweating) } & \multirow[t]{3}{*}{$P$-value ${ }^{a}$} & \multirow[t]{3}{*}{ P-value } \\
\hline & \multicolumn{3}{|c|}{ Seldom/never $(\mathrm{N}=2927)$} & \multicolumn{3}{|c|}{ Occasionally (N=1621) } & \multicolumn{3}{|c|}{ Often $(\mathrm{N}=328)$} & & \\
\hline & Mean & SD & $\begin{array}{c}\text { Frequency } \\
(\%)\end{array}$ & Mean & $S D$ & $\begin{array}{c}\text { Frequency } \\
(\%)\end{array}$ & Mean & SD & $\begin{array}{l}\text { Frequency } \\
(\%)\end{array}$ & & \\
\hline \multicolumn{12}{|l|}{ Leisure time physical activity } \\
\hline $\begin{array}{l}\text { Low } \\
\text { Moderate } \\
\text { High }\end{array}$ & $\dot{.}$ & . & $\begin{array}{l}16.9 \\
72.9 \\
10.2\end{array}$ & . & . & $\begin{array}{l}15.6 \\
73.6 \\
10.8\end{array}$ & & $\begin{array}{r}21.4 \\
68.8 \\
9.7\end{array}$ & $\dot{.}$ & 0.91 & 0.18 \\
\hline \multicolumn{12}{|l|}{ Smoker } \\
\hline $\begin{array}{l}\text { Current } \\
\text { Previous } \\
\text { Never }\end{array}$ & $\dot{.}$ & : & $\begin{array}{r}69.3 \\
21.0 \\
9.7\end{array}$ & . & . & $\begin{array}{r}74.9 \\
16.6 \\
8.5\end{array}$ & . & : & $\begin{array}{r}76.5 \\
15.9 \\
7.6\end{array}$ & $<0.001$ & $<0.001$ \\
\hline \multicolumn{12}{|l|}{ Alcohol, beverages per 24 hours } \\
\hline $\begin{array}{l}0 \\
1-2 \\
3-5 \\
\geq 6\end{array}$ & $\begin{array}{l}\dot{ } \\
\dot{.}\end{array}$ & : & $\begin{array}{r}37.1 \\
49.6 \\
11.3 \\
2.0\end{array}$ & $\begin{array}{l}. \\
\dot{.}\end{array}$ & : & $\begin{array}{r}29.4 \\
44.8 \\
21.6 \\
3.8\end{array}$ & i. & i. & $\begin{array}{l}24.1 \\
39.2 \\
26.2 \\
10.7\end{array}$ & $<0.001$ & $<0.001$ \\
\hline Age (years) & 48.7 & 5.3 & . & 48.5 & 5.4 & . & 48.5 & 5.3 & . & 0.27 & 0.54 \\
\hline Body mass index 1971 (kg/m²) & 24.9 & 2.8 & . & 25.8 & 3.1 & . & 26.3 & 3.2 & . & $<0.001$ & 0.10 \\
\hline Low social class (classes IV/V) & . & . & 38.1 & . & . & 81.1 & . & . & 82.6 & $<0.001$ & $<0.001$ \\
\hline \multicolumn{12}{|l|}{ Clinical risk factors } \\
\hline $\begin{array}{l}\text { Diabetes }^{c} \\
\text { Systolic BP mm Hg } \\
\text { Diastolic BP mm Hg } \\
\text { Hypertension }^{d}\end{array}$ & $\begin{array}{r}. \dot{ } \\
134.5 \\
83.0 \\
.\end{array}$ & $\begin{array}{r}. \dot{9} \\
11.7 \\
.\end{array}$ & $\begin{array}{r}0.8 \\
. \\
1.9\end{array}$ & $\begin{array}{r}135.3 \\
83.0 \\
.\end{array}$ & $\begin{array}{r}. \\
19.2 \\
11.5 \\
.\end{array}$ & $\begin{array}{r}0.6 \\
\dot{ } \\
1.3\end{array}$ & $\begin{array}{r}134.2 \\
83.5 \\
.\end{array}$ & $\begin{array}{r}. \dot{ } \\
19.4 \\
10.7 \\
.\end{array}$ & $\begin{array}{r}1.6 \\
\dot{\cdot} \\
0.9\end{array}$ & $\begin{array}{l}0.70 \\
0.58 \\
0.55 \\
0.05\end{array}$ & $\begin{array}{l}0.29 \\
0.22 \\
0.53 \\
0.17\end{array}$ \\
\hline
\end{tabular}

a P-values of trend test (Kendall's tau B) or test for linearity in analysis of variance.

b P-values of Chi-square test or test for deviation in analysis of variance.

c Receives doctor's treatment due to diabetes.

${ }^{d}$ Receives doctor's treatment due to hypertension. 
activity. Likewise, we observed only minor but significant differences in the degree of smoking between male workers with different levels of occupational physical activity. However, we found a strong association between the consumption of alcohol and occupational physical activity. No significant relations between the level of occupational physical activity and age, body mass index, diabetes, systolic and diastolic blood pressure, and hypertension were seen.

We observed similar associations between lifestyle and other characteristics and the level of strenuous work (table 2). The only difference was that we found no significant relation between the levels of strenuous work and physical activity during leisure time.

Among workers reporting a high compared to a low level of physical activity during leisure time, a lower fraction were current smokers, consumed $>6$ beverages/day of alcohol, received treatment for diabetes, or belonged to a low social class (table 3 ).

Workers reporting a moderate/high level of occupational physical activity and occasionally/often performing strenuous work had a significantly increased risk for IHD mortality compared with workers with a low level of occupational physical activity and seldom/never performing strenuous work (table 4). Specifically, workers with high level of occupational physical activity are at $50 \%$ increased risk, and workers often performing strenuous work are at $80 \%$ increased risk for IHD mortality compared with workers with low level of occupational physical activity and seldom/never performing strenuous work.

In contrast, workers reporting moderate or high level of physical activity during leisure time have a lowered risk for both IHD mortality and all-cause mortality compared with workers reporting low levels of such activity. Of particular interest is the $50 \%$ reduced risk for IHD mortality when having a high compared to low level of physical activity during leisure time.

For male workers with low physical work demands, the level of leisure time physical activity significantly modified the risk for IHD mortality in the following 30 years when we adjusted for lifestyle and social class, but not when we adjusted for clinical and all potential confounders. Among male workers with moderate physical work demands, the hazard ratio for IHD mortality adjusted for all confounders was 0.37 (95\% CI, $0.19-0.70$ ) for a high level of physical activity during leisure time and $0.79(95 \% \mathrm{CI}, 0.59-1.05)$ for a moderate level, compared with workers engaged in a low level of activity. After adjustment for a number of possible confounders (ie, age, blood pressure, smoking, alcohol, body mass index, diabetes, hypertension, and social

Table 3. Lifestyle and other characteristics stratified on leisure time physical activity among men without history of myocardial infarction, angina pectoris, or intermittent claudication.

\begin{tabular}{|c|c|c|c|c|c|c|c|c|c|c|c|}
\hline \multirow[t]{3}{*}{ Lifestyle factors 1970-1971 } & \multicolumn{9}{|c|}{ Level of leisure time physical activity } & \multirow[t]{3}{*}{$\mathrm{P}$-value ${ }^{\mathrm{a}}$} & \multirow[t]{3}{*}{$P$-value ${ }^{b}$} \\
\hline & \multicolumn{3}{|c|}{ Low $(\mathrm{N}=814)$} & \multicolumn{3}{|c|}{ Moderate $(\mathrm{N}=3514)$} & \multicolumn{3}{|c|}{ High $(N=504)$} & & \\
\hline & Mean & $\mathrm{SD}$ & $\begin{array}{c}\text { Frequency } \\
(\%)\end{array}$ & Mean & $\mathrm{SD}$ & $\begin{array}{c}\text { Frequency } \\
(\%)\end{array}$ & Mean & $\mathrm{SD}$ & $\begin{array}{c}\text { Frequency } \\
(\%)\end{array}$ & & \\
\hline \multicolumn{12}{|l|}{ Smoking } \\
\hline Current & $\cdot$ & . & 78.0 & $\cdot$ & . & 71.1 & $\cdot$ & . & 65.5 & & \\
\hline Previous & . & . & 14.9 & . & . & 19.8 & . & . & 21.4 & $<0.001$ & $<0.001$ \\
\hline Never & $\cdot$ & . & 7.1 & . & . & 9.1 & $\cdot$ & . & 13.1 & & \\
\hline \multicolumn{12}{|l|}{ Alcohol, beverages per 24 hours } \\
\hline 0 & . & . & 31.1 & . & . & 34.2 & . & . & 35.9 & & \\
\hline $1-2$ & . & . & 42.6 & . & . & 48.1 & . & . & 51.0 & $<0.001$ & $<0.001$ \\
\hline $3-5$ & . & . & 20.3 & . & . & 15.2 & . & . & 10.6 & & \\
\hline$\geq 6$ & $\cdot$ & . & 5.9 & . & . & 2.5 & . & . & 2.6 & & \\
\hline Age (years) & 49.3 & 5.5 & . & 48.6 & 5.2 & . & 47.5 & 5.2 & . & $<0.001$ & 0.21 \\
\hline Body mass index $1971\left(\mathrm{~kg} / \mathrm{m}^{2}\right)$ & 25.6 & 3.3 & . & 25.3 & 2.9 & . & 24.8 & 2.8 & . & $<0.001$ & 0.47 \\
\hline Low social class, $\%$ & $\cdot$ & . & 61.8 & $\cdot$ & . & 54.0 & . & . & 47.9 & $<0.001$ & $<0.001$ \\
\hline \multicolumn{12}{|l|}{ Clinical risk factors } \\
\hline Diabetes $^{c}$ & . & . & 1.5 & . & . & 0.5 & . & . & 1.0 & 0.21 & 0.02 \\
\hline Systolic blood pressure (mm Hg) & 135.3 & 19.7 & . & 134.7 & 18.8 & . & 132.5 & 17.7 & . & 0.02 & 0.24 \\
\hline Diastolic blood pressure (mm Hg) & 83.8 & 11.8 & . & 83.0 & 11.4 & . & 80.8 & 10.7 & . & $<0.001$ & 0.06 \\
\hline Hypertensiond & . & . & 2.1 & . & . & 1.7 & . & . & 0.6 & 0.04 & 0.06 \\
\hline
\end{tabular}

a P-values of trend test (Kendall's tau B) or test for linearity in analysis of variance.

b P-values of Chi-square test or test for deviation in analysis of variance.

${ }^{c}$ Receives doctor's treatment due to diabetes.

${ }^{d}$ Receives doctor's treatment due to hypertension. 
Table 4. Occupational and leisure time physical activity as predictors for ischemic heart disease mortality and all-cause mortality from 1970-1971 to end of 2001 among men without history of myocardial infarction, angina pectoris or intermittent claudication at baseline. ( $\mathrm{HR}=$ hazard ratio; $95 \% \mathrm{Cl}=95 \%$ confidence interval)

\begin{tabular}{|c|c|c|c|c|c|}
\hline & \multicolumn{2}{|c|}{ Mortality } & \multirow[t]{2}{*}{ Incidence ${ }^{\mathrm{a}}$} & \multirow[t]{2}{*}{$\mathrm{HR}^{\mathrm{b}}$} & \multirow[t]{2}{*}{$95 \% \mathrm{Cl}$} \\
\hline & N & $\%$ & & & \\
\hline \multicolumn{6}{|c|}{ Ischemic heart disease mortality } \\
\hline \multicolumn{6}{|l|}{ Physical work activity } \\
\hline $\begin{array}{l}\text { Low }(\mathrm{N}=1415) \\
\text { Moderate }(\mathrm{N}=2526) \\
\text { High }(\mathrm{N}=905)\end{array}$ & $\begin{array}{l}138 \\
313 \\
117\end{array}$ & $\begin{array}{r}9.8 \\
12.4 \\
12.9\end{array}$ & $\begin{array}{l}378 \\
498 \\
535\end{array}$ & $\begin{array}{l}1^{\mathrm{c}} \\
1.39 \\
1.51\end{array}$ & $\begin{array}{l}1.13-1.69 \\
1.18-1.94\end{array}$ \\
\hline \multicolumn{6}{|c|}{ Strenuous work (work resulting in sweating) } \\
\hline $\begin{array}{l}\text { Seldom/never }(N=2927) \\
\text { Occasionally }(N=1621) \\
\text { Often }(N=328)\end{array}$ & $\begin{array}{r}307 \\
224 \\
53\end{array}$ & $\begin{array}{l}10.5 \\
13.8 \\
16.2\end{array}$ & $\begin{array}{l}412 \\
573 \\
675\end{array}$ & $\begin{array}{l}1^{c} \\
1.49 \\
1.80\end{array}$ & $\begin{array}{l}1.25-1.77 \\
1.35-2.42\end{array}$ \\
\hline \multicolumn{6}{|l|}{ Leisure time physical activity } \\
\hline $\begin{array}{l}\text { Low }(\mathrm{N}=814) \\
\text { Moderate }(\mathrm{N}=3514) \\
\text { High }(\mathrm{N}=504)\end{array}$ & $\begin{array}{r}128 \\
398 \\
40\end{array}$ & $\begin{array}{r}15.7 \\
11.4 \\
8.0\end{array}$ & $\begin{array}{l}667 \\
449 \\
304\end{array}$ & $\begin{array}{l}1^{c} \\
0.67 \\
0.49\end{array}$ & $\begin{array}{l}0.55-0.82 \\
0.34-0.70\end{array}$ \\
\hline \multicolumn{6}{|l|}{ All-cause mortality } \\
\hline \multicolumn{6}{|l|}{ Physical work activity } \\
\hline $\begin{array}{l}\text { Low }(\mathrm{N}=1415) \\
\text { Moderate }(\mathrm{N}=2526) \\
\text { High }(\mathrm{N}=905)\end{array}$ & $\begin{array}{r}681 \\
1374 \\
542\end{array}$ & $\begin{array}{l}48.3 \\
54.5 \\
59.9\end{array}$ & $\begin{array}{l}1864 \\
2188 \\
2479\end{array}$ & $\begin{array}{l}1^{\mathrm{c}} \\
1.24 \\
1.43\end{array}$ & $\begin{array}{l}1.13-1.36 \\
1.28-1.61\end{array}$ \\
\hline \multicolumn{6}{|c|}{ Strenuous work (work resulting in sweating) } \\
\hline $\begin{array}{l}\text { Seldom/never ( } N=2927) \\
\text { Occasionally }(N=1621) \\
\text { Often }(N=328)\end{array}$ & $\begin{array}{r}1478 \\
956 \\
199\end{array}$ & $\begin{array}{l}50.7 \\
59.1 \\
60.9\end{array}$ & $\begin{array}{l}1983 \\
2446 \\
2536\end{array}$ & $\begin{array}{l}1^{c} \\
1.33 \\
1.42\end{array}$ & $\begin{array}{l}1.23-1.44 \\
1.22-1.64\end{array}$ \\
\hline \multicolumn{6}{|l|}{ Leisure time physical activity } \\
\hline $\begin{array}{l}\text { Low }(\mathrm{N}=814) \\
\text { Moderate }(\mathrm{N}=3514) \\
\text { High }(\mathrm{N}=504)\end{array}$ & $\begin{array}{r}526 \\
1845 \\
218\end{array}$ & $\begin{array}{l}64.6 \\
52.6 \\
43.5\end{array}$ & $\begin{array}{l}2742 \\
2084 \\
1659\end{array}$ & $\begin{array}{l}1^{c} \\
0.74 \\
0.62\end{array}$ & $\begin{array}{l}0.67-0.82 \\
0.53-0.72\end{array}$ \\
\hline
\end{tabular}

a Per 100000 person years at risk.

${ }^{\mathrm{b}}$ Adjusted for age.

${ }^{\mathrm{c}}$ Reference.

class), the hazard ratio for IHD mortality among workers with high physical work demands was $0.82(95 \% \mathrm{CI}$, $0.42-1.56)$ for those with high levels of physical activity during leisure time and $0.62(95 \% \mathrm{CI}, 0.40-0.97)$ for a moderate level, compared to workers with a low level of activity (table 5). Accordingly, workers with high physical work demands and engaged in moderate physical activity during leisure time had a $38 \%$ lower risk of IHD mortality than workers with a low level of physical activity during leisure time.

For male workers with low physical work demands, the hazard ratio for all-cause mortality adjusted for all confounders was 0.81 (95\% CI, 0.66-0.98) for a moderate level of physical activity during leisure time and 0.81 (95\% CI, 0.60-1.11) for a high level, compared with workers engaged in a low level of such activity (table 5). For male workers with moderate physical work demands, the hazard ratio for all-cause mortality adjusted for all confounders was 0.82 (95\% CI, 0.710.94 ) for a moderate level of physical activity during leisure time and $0.64(95 \% \mathrm{CI}, 0.50-0.81)$ for a high level compared with workers engaged in a low level of such activity. For male workers with high physical work demands, the level of physical activity during leisure time did not significantly modify the risk of all-cause mortality in the following 30 years.

To further elucidate and test the hypothesis that being physically active in leisure time might be a risk factor among men with high physical work demands, we compared those sedentary at leisure time with those who were moderately or highly active in leisure time stratified into three groups, according to physical work demands, using the same stratification as in table 5.

As shown in table 6, men who were moderately or highly physically active at leisure time, had a decreased risk of IHD mortality in all groups, when adjusting for age alone, both lifestyle and social class, and for all confounders included; with one exception only, the association reached statistical significance. With respect to all-cause mortality, a similar pattern was observed within all three groups, however, not reaching statistical significance when controlling for confounding factors among men with the highest work demands. Also the strength of the association was somewhat smaller.

\section{Discussion}

A high level of physical activity during leisure time was not associated with an increased risk of IHD mortality or all-cause mortality. On the contrary, among men with moderate and high physical work demands, being either moderately or highly active during leisure time reduced the risk of IHD mortality. The most pronounced trend was observed for those with moderate physical work demands. Accordingly, the hypothesis was proven false.

The findings of this study are in agreement with a number of previous studies on the relationship between physical work activity and cardiovascular health (17-21), but not with a considerable part of the scientific literature (12-14). The discrepancy in the scientific literature on the relationship between physical work activity and cardiovascular health may be due to a number of reasons. Likely explanations may be discrepancies in the assessment of physical activity at work, outcome on cardiovascular disease, the study population, included work groups, length of follow-up, and confounder control.

A methodological limitation of this study is that the information on physical activity in the workplace and during leisure time was based on self-assessment, which invariably entails some degree of misclassification (30). 
Table 5. Leisure time physical activity (1970-1971) and risk for ischemic heart disease (IHD) and all-cause mortality from 1970/1971 to end of 2001 stratified into levels of physical work demands (combination of level of occupational physical activity and occurrence of physically strenuous work). Different adjustment criteria are applied in Cox proportional hazards regression analyses with forced entry of variables. ( $\mathrm{HR}=$ hazard ratios, $95 \% \mathrm{Cl}=95 \%$ confidence intervals.)

\begin{tabular}{|c|c|c|c|c|c|c|c|c|c|c|c|c|}
\hline \multirow{3}{*}{$\begin{array}{l}\text { Leisure time physical } \\
\text { activity (1970-1971) }\end{array}$} & \multicolumn{6}{|c|}{ IHD mortality } & \multicolumn{6}{|c|}{ All-cause mortality } \\
\hline & \multicolumn{2}{|c|}{$\begin{array}{l}\text { Crude } \\
\text { incidence }\end{array}$} & \multirow[t]{2}{*}{$\mathrm{HR}^{\mathrm{a}}$} & \multirow[t]{2}{*}{$95 \% \mathrm{Cl}$} & \multirow[t]{2}{*}{$\mathrm{HR}^{\mathrm{b}}$} & \multirow[t]{2}{*}{$95 \% \mathrm{Cl}$} & \multicolumn{2}{|c|}{$\begin{array}{l}\text { Crude } \\
\text { incidence }\end{array}$} & \multirow[t]{2}{*}{$\mathrm{HR}^{\mathrm{a}}$} & \multirow[t]{2}{*}{$95 \% \mathrm{Cl}$} & \multirow[t]{2}{*}{$\mathrm{HR}^{\mathrm{b}}$} & \multirow[t]{2}{*}{$95 \% \mathrm{Cl}$} \\
\hline & $\%$ & $\begin{array}{l}\text { Person- } \\
\text { years }^{b}\end{array}$ & & & & & $\%$ & $\begin{array}{l}\text { Person- } \\
\text { years }^{b}\end{array}$ & & & & \\
\hline \multicolumn{13}{|c|}{ Low physical work demands ( $N=1236$ ) } \\
\hline Low $(\mathrm{N}=234)$ & 13.7 & 557 & $1^{d}$ & - & $1^{d}$ & 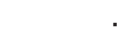 & 61.1 & 2491 & $1^{d}$ & . & $1^{d}$ & . \\
\hline Moderate $(\mathrm{N}=870)$ & 9.0 & 344 & $0.62^{e}$ & $0.41-0.94$ & 0.72 & $0.47-1.10$ & 45.4 & 1735 & $0.70^{\dagger}$ & $0.57-0.84$ & $0.81 \mathrm{e}$ & $0.66-0.98$ \\
\hline High $(\mathrm{N}=132)$ & 9.8 & 373 & 0.67 & $0.55-1.29$ & 0.61 & $0.30-1.26$ & 46.2 & 1751 & $0.70^{\mathrm{e}}$ & $0.51-0.94$ & 0.81 & $0.60-1.11$ \\
\hline \multicolumn{13}{|c|}{ Moderate physical work demands ( $\mathrm{N}=2651)$} \\
\hline Low $(\mathrm{N}=414)$ & 15.2 & 650 & $1^{d}$ & . & $1^{d}$ & . & 64.0 & 2736 & $1^{d}$ & . & $1^{d}$ & . \\
\hline Moderate $(\mathrm{N}=1994)$ & 12.1 & 481 & $0.72^{e}$ & $0.54-0.94$ & 0.79 & $0.59-1.05$ & 53.9 & 2144 & $0.74^{\dagger}$ & $0.65-0.85$ & $0.82^{g}$ & $0.71-0.94$ \\
\hline High $(N=243)$ & 4.6 & 170 & $0.28^{\dagger}$ & $0.15-0.33$ & $0.37^{9}$ & $0.19-0.70$ & 38.3 & 1428 & $0.52^{\dagger}$ & $0.41-0.67$ & $0.64^{\dagger}$ & $0.50-0.81$ \\
\hline \multicolumn{13}{|c|}{ High physical work demands ( $\mathrm{N}=858$ ) } \\
\hline Low $(\mathrm{N}=148)$ & 20.3 & 903 & $1^{d}$ & & $1^{d}$ & & 72.3 & 3223 & $1^{d}$ & . & $1^{d}$ & . \\
\hline Moderate $(\mathrm{N}=595)$ & 12.8 & 530 & $0.65^{\mathrm{e}}$ & $0.42-0.99$ & $0.62^{\mathrm{e}}$ & $0.40-0.97$ & 60.0 & 2492 & 0.82 & $0.66-1.02$ & 0.90 & $0.71-1.12$ \\
\hline High $(\mathrm{N}=115)$ & 13.0 & 519 & 0.69 & $0.37-1.30$ & 0.82 & $0.42-1.56$ & 50.4 & 2009 & $0.69 \mathrm{e}$ & $0.50-0.95$ & 0.84 & $0.60-1.18$ \\
\hline
\end{tabular}

${ }^{\text {a }}$ Adjusted for age.

${ }^{b}$ Adjusted for all potential confounders: age, body mass index, systolic blood pressure, diastolic blood pressure, treatment of diabetes or hypertension, alcohol use, smoking (current, never, previous), social class (classes IV/V versus I, II, III).

c Per 100000 person-years at risk.

d Reference.

e $P \leq 0.05$.

${ }^{+} P \leq 0.001$

${ }^{g} \mathrm{P} \leq 0.01$.

Table 6. A sedentary lifestyle in leisure time 1970-1971 (low leisure time physical activity) and risk for ischemic heart disease IHD and all-cause mortality from 1970/1971 to end of 2001 stratified into levels of physical work demands (combination of level of occupational physical activity and occurrence of physically strenuous work). Different adjustment criteria are applied in Cox proportional hazards regression analyses with forced entry of variables. ( $\mathrm{HR}=$ hazard ratios, $95 \% \mathrm{Cl}=95 \%$ confidence intervals.)

\begin{tabular}{|c|c|c|c|c|c|c|c|c|c|c|c|c|}
\hline \multirow{2}{*}{$\begin{array}{l}\text { Leisure time } \\
\text { physical } \\
\text { activity } \\
(1970-1971)\end{array}$} & \multicolumn{6}{|c|}{ IHD mortality } & \multicolumn{6}{|c|}{ All-cause mortality } \\
\hline & $\begin{array}{l}\text { HR } \\
\text { adjusted } \\
\text { for age }\end{array}$ & $95 \% \mathrm{Cl}$ & $\begin{array}{c}\mathrm{HR} \\
\text { adjusted } \\
\text { for age } \\
\text { lifestyle and } \\
\text { social class }\end{array}$ & $95 \% \mathrm{Cl}$ & $\begin{array}{c}\text { HR } \\
\text { adjusted } \\
\text { for all } \\
\text { potential } \\
\text { confounders }\end{array}$ & $\begin{array}{l}95 \% \mathrm{Cl} \\
\mathrm{S}^{\mathrm{a}}\end{array}$ & $\begin{array}{l}\text { HR } \\
\text { adjusted } \\
\text { for age }\end{array}$ & $95 \% \mathrm{Cl}$ & $\begin{array}{c}H R \\
\text { adjusted } \\
\text { for age } \\
\text { lifestyle an } \\
\text { social clas }\end{array}$ & $\begin{array}{l}95 \% \mathrm{Cl} \\
\text { id } \\
\text { ss }\end{array}$ & $\begin{array}{c}\text { HR } \\
\text { adjusted } \\
\text { for all } \\
\text { potential } \\
\text { confounders }\end{array}$ & $95 \% \mathrm{Cl}$ \\
\hline \multicolumn{13}{|c|}{ Low physical work demands ( $\mathrm{N}=1236)$} \\
\hline $\begin{array}{l}\text { Low }(\mathrm{N}=234) \\
\text { Moderate/ } \\
\text { high }(\mathrm{N}=1002)\end{array}$ & $0.63^{\mathrm{c}}$ & $0.42-0.95$ & $\begin{array}{r}1^{b} \\
0.64^{c}\end{array}$ & $0.43-0.97$ & $\begin{array}{r}1^{\mathrm{b}} \\
0.70\end{array}$ & $0.47-1.07$ & $0.70^{d}$ & $0.58-0.84$ & $0.74^{\mathrm{e}}$ & $0.61-0.90$ & $0.81^{\mathrm{c}}$ & $0.66-0.98$ \\
\hline \multicolumn{13}{|c|}{ Moderate physical work demands $(\mathrm{N}=2651)$} \\
\hline $\begin{array}{l}\text { Low }(\mathrm{N}=414) \\
\text { Moderate/ } \\
\text { high }(\mathrm{N}=2237)\end{array}$ & $0.67^{d}$ & $0.51-0.88$ & $\begin{array}{r}1^{\mathrm{b}} \\
0.70^{\mathrm{e}}\end{array}$ & $0.53-0.93$ & $\begin{array}{r}1^{\mathrm{b}} \\
0.75^{\mathrm{c}}\end{array}$ & $0.56-1.0$ & $0.72^{d \mathrm{~d}}$ & $0.63-0.83$ & $0.77^{d \mathrm{~d}}$ & $0.68-0.89$ & $0.80^{1^{b}}$ & $0.70-0.92$ \\
\hline \multicolumn{13}{|c|}{ High physical work demands ( $\mathrm{N}=858$ ) } \\
\hline $\begin{array}{l}\text { Low }(\mathrm{N}=148) \\
\text { Moderate/ } \\
\text { high }(\mathrm{N}=710)\end{array}$ & $0.66^{c}$ & $0.43-0.997$ & $0.64^{c}$ & $0.42-0.97$ & $0.65^{\mathrm{c}}$ & $0.42-1.0$ & $0.80^{c}$ & $0.65-0.99$ & $\begin{array}{r}1^{b} \\
0.85\end{array}$ & $0.68-1.05$ & $\begin{array}{r}1^{\mathrm{b}} \\
0.89\end{array}$ & $0.71-1.11$ \\
\hline
\end{tabular}

${ }^{a}$ Age, body mass index, systolic blood pressure, diastolic blood pressure, treatment of diabetes or hypertension, alcohol use, smoking (current, never, previous), social class (classes IV/N versus I, II, III).

b Reference.

c $\mathrm{P} \leq 0.05$.

d $P \leq 0.001$.

e $\mathrm{P} \leq 0.01$. 
However, no technical equipment for measuring daily physical activity at work and during leisure time was available in 1970, at least not in Denmark. In addition, the lack of continuous exposure data and repeated measures of exposure during the relatively long follow-up period may have contributed to misclassification of exposure. The study population of the Copenhagen Male Study comprised urban Danish male workers aged 40-59 years in 1970-1971. It is unknown whether the findings of this study also apply to women, workers with different levels of physical fitness, younger workers and workers from other (eg, rural) communities or of different nationalities. For example, it would be of particular interest to investigate whether high physical work demands have similar negative effects on IHD mortality among workers with high versus low physical fitness.

This study indicates that physical activity at work enhances the risk for IHD and all-cause mortality. The study found no harmful effects of physical activity during leisure time for IHD and all-cause mortality. However, these risks could not be ruled out, especially for men with pre-existing cardiovascular disease or those with high physical job demands.

In conclusion, among men without pre-existing clinical cardiovascular disease, the hypothesis tested was not supported. Physical activity during leisure time did not increase the risk for either IHD or all-cause mortality. In contrast, moderate and high levels of leisure time physical activity seemed to protect against IHD mortality among people with moderate and high physical activity at work.

\section{References}

1. Leitzmann MF, Park Y, Blair A, Ballard-Barbash R, Mouw T, Hollenbeck AR, et al. Physical activity recommendations and decreased risk of mortality. Arch Intern Med. 2007;167(22):2453-60.

2. Lee IM, Skerrett PJ. Physical activity and all-cause mortality: what is the dose-response relation? Med Sci Sports Exerc. 2001;33(6):S459-S471

3. Sesso HD, Paffenbarger RS Jr, Lee IM. Physical activity and coronary heart disease in men : the Harvard Alumni Health Study. Circulation. 2000;102(9):975-80.

4. Kujala UM, Kaprio J, Sarna S, Koskenvuo M. Relationship of leisure-time physical activity and mortality: the Finnish twin cohort. JAMA. 1998;279(6):440-4.

5. Mokdad AH, Marks JS, Stroup DF, Gerberding JL. Actual causes of death in the United States, 2000. JAMA. 2005;293(3):293-4.

6. Powell KE, Blair SN. The public-health burdens of sedentary living habits - theoretical but realistic estimates. Med Sci Sports Exerc. 1994;26(7):851-6.
7. Morris JN, Clayton DG, Everitt MG, Semmence AM, Burgess EH. Exercise in leisure time: coronary attack and death rates. Br Heart J. 1990;63(6):325-34.

8. Lissner L, Bengtsson C, Bjorkelund C, Wedel H. Physical activity levels and changes in relation to longevity: a prospective study of Swedish women. Am J Epidemiol. 1996;143(1):54-62.

9. Rosengren A, Wilhelmsen L. Physical activity protects against coronary death and deaths from all causes in middle aged men - evidence from a 20-year follow-up of the primary prevention study in Goteborg. Ann Epidemiol. 1997;7(1):69-75.

10. Wannamethee SG, Shaper AG, Walker M. Changes in physical activity, mortality, and incidence of coronary heart disease in older men. Lancet. 1998;351(9116):1603-8.

11. Physical activity guidelines advisory committee. Physical activity guidelines advisory committee report. Washington (DC): US Department of Health and Human Services; 2008.

12. $\mathrm{Hu}$ G, Jousilahti P, Borodulin K, Barengo NC, Lakka TA, Nissinen A, et al. Occupational, commuting and leisure-time physical activity in relation to coronary heart disease among middle-aged Finnish men and women. Atherosclerosis. 2007;194(2):490-7.

13. Salonen JT, Slater JS, Tuomilehto J, Rauramaa RAIN. Leisure time and occupational physical activity: risk of death from ischemic heart disease. Am J Epidemiol. 1988;127(1):87-94.

14. Barengo NC, Hu G, Lakka TA, Pekkarinen H, Nissinen A, Tuomilehto J. Low physical activity as a predictor for total and cardiovascular disease mortality in middle-aged men and women in Finland. Eur Heart J. 2004;25(24):2204-11.

15. Andersen LB, Schnohr P, Schroll M, Hein HO. All-cause mortality associated with physical activity during leisure time, work, sports, and cycling to work. Arch Intern Med. 2000;160(11):1621-8.

16. Proper KI, Hildebrandt VH. Physical activity among Dutch workers - differences between occupations. Prev Med. 2006;43(1):42-5.

17. Raum E, Rothenbacher D, Ziegler H, Brenner H. Heavy physical activity: risk or protective factor for cardiovascular disease? a life course perspective. Ann Epidemiol. 2007;17(6):417-24.

18. Krause N, Brand RJ, Kaplan GA, Kauhanen J, Malla S, Tuomainen T-P, et al. Occupational physical activity, energy expenditure and 11-year progression of carotid atherosclerosis. Scand J Work Environ Health. 2007;33(6):405-24.

19. Stender M, Hense HW, Doring A, Keil U. Physical-activity at work and cardiovascular-disease risk - results from the Monica Augsburg Study. Int J Epidemiol. 1993;22(4):644-50.

20. Kannel WB, Belanger A, D’Agostino R, Israel I. Physical activity and physical demand on the job and risk of cardiovascular disease and death: The Framingham Study. Am Heart J 1986;112(4):820-5.

21. Kristal-Boneh E, Harari G, Melamed S, Froom P. Association of physical activity at work with mortality in Israeli industrial employees: The CORDIS study. J Occup Environ Med. 2000;42(2):127-35. 
22. Struensee JF. De incongrui corporis motus insalubritate [On unhealthy bodily movements]. Litteris Gebauerianis (Halae); 1757.

23. Virkkunen H, Härmä M, Kauppinen T, Tenkanen L. Shift work, occupational noise and physical workload with ensuing development of blood pressure and their joint effect on the risk of coronary heart disease. Scand J Work Environ Health. 2007;33(6):425-34.

24. Glagov S, Zarins C, Giddens DP, Ku DN. Hemodynamics and atherosclerosis - insights and perspectives gained from studies of human arteries. Arch Pathol Lab Med. 1988;112(10):1018-31.

25. Gyntelberg F. Physical fitness and coronary heart disease in male residents in Copenhagen aged 40-59. Dan Med Bull. 1973;20(1):1-4.

26. Gyntelberg F. One-year and 2-years incidence of myocardial- infarction in Copenhagen males aged 40-59. Dan Med Bull. 1975;22(2):81-4.

27. Hein HO, Suadicani P, Gyntelberg F. Ischaemic heart disease incidence by social class and form of smoking: the Copenhagen Male Study - 17 years' follow-up. J Intern Med. 1992;231(5):477-83.

28. Svalastoga K. Prestige, class and mobility. Copenhagen: Munksgaard; 1959.

29. Hansen EJ. Socialgrupper i Danmark. [Social groups in Denmark]. Copenhagen: Socialforskningsinstituttet, 1984.

30. Sallis JF, Saelens BE. Assessment of physical activity by selfreport: status, limitations, and future directions. Res Q Exerc Sport. 2000;71(2):S1-S14

Received for publication: 25 May 2009 